\title{
Prevalence of Eating Disorders among Female Undergraduates at a Nigerian University
}

\section{Adebimpe Oluwafisayo A ${ }^{1}$, Idehen $\mathrm{EE}^{2}$, Mosaku SK ${ }^{3}$, Muoghalu CO${ }^{4}$, Opakunle $\mathbf{T}^{5}$}

\author{
${ }^{1}$ Department of Psychiatry, College of Health Sciences, Ladoke Akintola University of Technology, Ogbomoso, \\ Oyo State. \\ ${ }^{2}$ Department of Psychology, Faculty of Social Sciences, Obafemi Awolowo University Ile-Ile, Osun State. \\ ${ }^{3}$ Department of Mental Health, College of Health Sciences, Obafemi Awolowo University Ile Ife, Osun State. \\ ${ }^{4}$ Department of Sociology and Anthropology, Faculty of Social Sciences, Obafemi Awolowo University, Ile-Ile, \\ Osun State. \\ ${ }^{5}$ Department of Mental Health, State Hospital, Osogbo, Osun State \\ Corresponding Author: Adebimpe Oluwafisayo A
}

\begin{abstract}
Eating disorder is not an uncommon disorder in developed countries, although this topic has been relatively understudied in developing countries. This study determined the prevalence of eating disorder and types of eating disorders common among female undergraduates in Obafemi Awolowo University, Ile-Ife. Using a descriptive survey design, 1000 female undergraduates aged 18-40years was selected through the stratified random sampling technique. Data were collected on sociodemographic variables such as age and religion, height and weight while, The Eating Attitudes Test (EAT) was used to measure eating disorders. Data was analyzed using descriptive and inferential statistical techniques. One hundred and seventy one (171) respondents were classified as highly at risk for eating disorders. The prevalence of eating disorder among the study population was $17.1 \%$. The results revealed that $205(20.5 \%)$ of the respondents were at risk for anorexia nervosa, $170(17.0 \%)$ for bulimia nervosa and $168(16.8 \%)$ for obesity. The study concluded that eating disorder is common among young adults in Nigeria.
\end{abstract}

Keywords: Eating disorders, Anorexia nervosa, Bulimia nervosa, Obesity, prevalence of eating disorders

\section{INTRODUCTION}

A Nigerian woman being significantly fat was considered physically attractive and sexually desirable about a century ago. However, with the advent of technology and modernization many adolescent girls imitate what is happening in the western world which has led to a compulsive desire to be slim through manipulating eating and sometimes resorting to physical exercise. Eating disorders are a major source of physical and psychosocial morbidity among young women ${ }^{12}$. Thus, it is important to detect those at risk of developing an eating disorder, with the view of preventing the disorder or initiating prompt treatment in those affected. This is because clinical experience and research evidence have indicated that eating disorders commonly begin with behaviour that resembles normal dieting, young women who are dieting constitute an important high-risk group, although only a small minority will develop an eating disorder ${ }^{3}$. Many whose body weights do not predispose to health problems seem to be weight conscious, primarily for cosmetic reasons. Their goal is to achieve a body size and shape that meets society's standards of perfection. 
Although for many decades it has been assumed that eating disorders occur primarily in Western cultures, particularly among adolescents in middle or upper socio-economic groups but there is growing evidence suggesting otherwise. In the past it was believed that non-western cultures are 'immune' to disordered eating attitudes. They tend to embrace plumpness and the larger figure which was rewarded with respect as it symbolizes beauty, wealth, fertility and femininity, ${ }^{45}$ as well as health and strength ${ }^{6}$. But this is contrary to Western cultures that tend to overvalue thinness ${ }^{7}$. Community-based samples conducted in some African countries during the $1980 \mathrm{~s}$ and $1990 \mathrm{~s}^{8}$ suggested that Western' epidemic of eating disorders has arrived on the African continent. It has been argued that these developments can largely be attributed to the process of acculturation. Many aspects of self-identity are modified to accommodate information on and experiences within the new culture.

However, studies of communitybased samples conducted in South Africa, Zimbabwe, Egypt and Nigeria during the 1980s and 1990s 910111213141516 provide support for the hypothesis that the 'Western' epidemic of eating disorders has arrived on the African continent. It has been argued that these developments can largely be attributed to the process of acculturation. Many aspects of self-identity are modified to accommodate information on and experiences within the new culture. Evidence suggests that rates of abnormal eating attitudes in black samples are higher than ${ }^{17}$ or equivalent ${ }^{8}$ to those in white samples, especially in South African urban settings. The prevalence of abnormal eating attitudes was equally common in black, mixed-race and white urban girls aged between 15 and 18 years ${ }^{18}$. Due to the fact that eating disorder behaviours have a major focus on social norms of attractiveness and weight control, it is imperative to focus on these factors.

Eating disorders became the third leading chronic illness among adolescent girls in the United States and other developed countries ${ }^{19}$ such as Canada 20 and Norway ${ }^{21}$. Although it has been argued that Eating Disorder are rare in non-Western communities in which plumpness is not stigmatised $^{22}$, Eating Disorder were documented in developing countries. ${ }^{23}$ For instance, the lifetime prevalence of Anorexia Nervosa and Bulimia Nervosa has been $0.9 \%$ and $3.2 \%$, respectively among adolescent girls in Iran ${ }^{24}$. Similarly, a study has addressed the occurrence of Eating Disorder in Saudi Arabian adolescent girls and stated that $19.6 \%$ of the girls had abnormal eating attitudes and $0.8 \%$ had Anorexia Nervosa ${ }^{23}$. Approximately, $10 \%$ of normal weight female college students in Lebanon have desired to be thin, are preoccupied with weight, have taken laxatives and diet pills, engaged in strenuous exercise, avoided high caloric foods, fasted, binged and skipped meals ${ }^{25}$. In the Western society, being thin (the ideal of beauty) is highly rated because it symbolizes certain notions such as social acceptance and success. Nonetheless, nonWestern populations have been found to place value on plumpness; a sign of beauty, fertility and good health ${ }^{22}$.

Bruch was one of the earliest researchers to link cultural elements to the escalating prevalence of eating disorders, citing both the vogue on insistence on slimness as well as the conflicting strain on contemporary young individuals to appear successful" as reasons for the confusion of self-identity ${ }^{26}$. Original investigations by Gardner and his colleagues and later confirmed that idealized depictions of the female figure in wide societal views became progressively skinnier and relatively less shapely from the early 1960s through the end of the 1990s. These unrealistic trends and unattainable standards of beauty have continued into the new millennium as well. Whether such media images play a contributory role in the onset of eating disorders or whether they simply represent the values of the wider culture is an issue of some controversy. Given the emphasis that 
body-image plays in the pathology of eating disorders' it seems unlikely that the association between the increasing demand for slenderness in society and the prevalence of eating disorders within such cultures are coincidental. It is plausible, however, that only persons who are susceptible to these demands, such as those with a history of anxiety, depression, low self-worth in their youth, established preoccupation with weight control, and possible inherited predispositions will react to these social pressures with the symptoms of anorexia or bulimia $^{28}$

The consequence of these contrasting demands has been, for many, a growing sense of insecurity and self-doubt, along with an emerging sense of powerlessness $^{29}$. The contradictory character of this uncertainty of self-identity, along with the prospect of improved conditions for opportunity is illustrated in the title of a work by Silverstein and Perlick in which they have posited that the thin body-type standards advertised in conventional sociological accounts of eating disorders can be described as body-type ideals that devalue customary feminine" shapeliness by shifting contemporary ideals to gender stereotypes that marginalize women by associating body curves with unattractiveness, low intelligence and laziness $^{30}$. It could be suggested that the contradiction and alterations in female selfidentity characterize the most profound foundation of eating disorders throughout history $^{31}$. This may account for the fact that eating disorders, as they have emerged in economically developed areas of the world, do not inevitably convey themselves only as self-image preoccupations, but rather portray a plethora of societal norms that may result in some common underlying psychological conflict. Conventional self perception among Africans has always leaned towards a robust, full-figured form as the model of beauty and success.

\section{SUBJECTS AND METHODS}

The study was a prospective crosssectional survey. A structured research instrument was used to obtain information. Data was generated and analyzed.

\section{SAMPLING PROCEDURE}

A stratified random sampling technique was used to select 1000 (approximately 15\%) of the consenting female undergraduates within the ages range 18 years to 40years. They were selected randomly from amongst female undergraduates between 100 to 600 year levels, residents at female hostels on the Obafemi Awolowo University Ile-Ife. Nigeria.

\section{MEASURES}

Eating Attitudes Test (EAT-26) developed by Garner and Garfinkel initially was a diagnostic test for anorexia nervosa, but used to detect eating disorders in general. It detects clinical case in high-risk populations and identifies individuals with an abnormal preoccupation with their diet and weight ${ }^{32}$. The original version was 40 items in the scale, the authors decided to leave out 14 , as they were considered to be redundant and did not increase predictive power. EAT-26, is simpler and more economic, being highly correlated with the original scale. It identifies individuals with anorexia nervosa, bulimia nervosa, and binge eating disorder.

\section{PROCEDURE}

The Eating Attitude Test (EAT) a 26 item scale was used to measure eating disorder in the study. The EAT was scored for its three dimensions of anorexia nervosa, bulimia nervosa and obesity as well as a global score. The global scores were used for the analysis. First, item scores across all of the 26 items were added together.

This total score ranged from zero (0) to 98 . The higher this total scores the more severe the symptoms of eating disorder selfreported by the respondent. Extreme scores of one standard deviation above and below 
the mean (that is, $\mathrm{M} \pm 1 \mathrm{SD}$ ) was then used to categorize the respondents into three groups on the basis of the severity of selfreported symptoms. The mean for this sample is 36.69 and the standard deviation is 16.90. With these figure one standard deviation above the mean (that is, $36.69+$ $16.90=53.59$ ) was determined to be a score of 54, while one standard deviation below the mean (that is, $36.69-16.90=19.79$ ) was determined to be score of 20 .
Respondents with scores in the range of zero (0) to 20 were regarded as having mild symptoms of eating disorders, those with scores in the range of 21 to 53 were categorized as having as having moderate symptoms of eating disorders and those who scored 54 and above were grouped into the severe symptoms of eating disorders group.

The norms for the sample are presented in Table 1

Table 1 Norms for the EAT in the Present Sample

\begin{tabular}{|c|c|l|l|l|l|}
\hline $\mathbf{M}$ & SD & M+ 1SD & M - 1SD & Score Range & Category \\
\hline 36.69 & 16.90 & 53.59 & \multirow{2}{*}{19.79} & $0-20$ & Mild level risk for developing eating disorder \\
\cline { 4 - 5 } & & & & $21-53$ & Moderate level risk for developing eating disorder \\
\cline { 4 - 6 } & & & & $54-130$ & Severe risk for developing eating disorder \\
\hline
\end{tabular}

The EAT-26 may also be given repeatedly throughout treatment as global measures of treatment progress ${ }^{33}$.

\section{RESULTS}

A total of 1000 female undergraduate student respondents were analyzed. The mean age of the student was 21.9 years with standard deviation of 3.38. Self-reported symptoms of eating disorders of such magnitude that they could be regarded as being at high risk for any of the eating disorders, was reported in $171(17 \%)$ out of the total 1000 population.

\section{Types of eating disorder common among the population}

The eating attitude test was scored separately for the three dimensions of anorexia nervosa, bulimia nervosa and obesity. The relevant data for these three types of eating disorders are presented in Table 2.

\begin{tabular}{|c|c|c|c|c|c|c|c|}
\hline Group & Score range & Frequency & Percentage & $\mathbf{M}$ & SD & M+1SD & M - 1SD \\
\hline \multirow{4}{*}{$\begin{array}{l}\text { Mild symptoms } \\
\text { Moderate symptoms } \\
\text { Severe symptoms } \\
\text { Total }\end{array}$} & $0-20$ & 180 & 18.0 & \multirow{3}{*}{36.69} & \multirow{3}{*}{16.90} & \multirow{3}{*}{53.59} & \multirow{3}{*}{19.79} \\
\hline & $21-53$ & 649 & 64.9 & & & & \\
\hline & $54-98$ & 171 & $17.1^{*}$ & & & & \\
\hline & $0-98$ & 1000 & 100.0 & & & & \\
\hline
\end{tabular}

The results presented in Table 2 indicates the $171(17.1 \%)$ of the female undergraduates included in the sample with Self-reported symptoms of eating disorders of such magnitude that they could be regarded as being at high risk for any of the eating disorders, was reported in $171(17 \%)$ out of the total 1000 population.

The categories of the eating disorders and the severities of the eating disorders were analyzed. Table 3 gives the full details of the analysis. The data indicates that the mean for anorexia nervosa is 10.73 with a standard deviation of 5.83 . The upper limit was therefore determined as a score of 17 and the lower limit as a score of 5 , therefore the respondents with scores of range zero (0) to five (5) were regarded as self-reporting mild symptoms of anorexia nervosa; those who scored six (6) to sixteen (16) were classified as self-reporting moderate symptoms of anorexia nervosa; and those with scores range seventeen (17) to thirty five (35) were categorized as selfreporting severe symptoms of anorexia nervosa. The mean for bulimia nervosa is 11.38 with a standard deviation of 6.45 . The upper limit was therefore determined as a score of 18 and the lower limit as a score of 5 , therefore the respondents with scores of 
range zero (0) to four (4) were regarded as self-reporting mild symptoms of bulimia nervosa; those who scored five (5) to seventeen (17) were classified as selfreporting moderate symptoms of bulimia nervosa and those with scores range eighteen (18) to thirty nine (39) were categorized as self-reporting severe symptoms of bulimia nervosa. The mean for obesity is 14.58 with a standard deviation of 7.40. The upper limit was therefore determined as a score of 22 and the lower limit as a score of 8, therefore the respondents with scores of range zero (0) to seven (7) were regarded as self-reporting mild symptoms of obesity; those who scored eight (8) to twenty one (21) were classified as self-reporting moderate symptoms of obesity; and those with scores range twenty two (22) to forty five (45) were categorized as self-reporting severe symptoms of obesity.

Table 3: Categories and Types of Eating Disorder among the population

\begin{tabular}{|c|c|c|c|c|c|c|c|c|}
\hline Type & Category & Frequency & Percentage & Score Range & M & SD & M+ 1SD & M-1SD \\
\hline Anorexia nervosa & $\begin{array}{l}\text { Mild } \\
\text { Moderate } \\
\text { Severe }\end{array}$ & $\begin{array}{l}187 \\
608 \\
205\end{array}$ & $\begin{array}{l}18.70 \\
60.80 \\
20.50\end{array}$ & $\begin{array}{c}0-5 \\
6-16 \\
17-35\end{array}$ & 10.73 & 5.83 & 16.56 & 4.90 \\
\hline Bulimia nervosa & $\begin{array}{l}\text { Mild } \\
\text { Moderate } \\
\text { Severe }\end{array}$ & $\begin{array}{l}188 \\
642 \\
170\end{array}$ & $\begin{array}{l}18.80 \\
64.20 \\
17.00\end{array}$ & $\begin{array}{c}0-4 \\
5-17 \\
18-39\end{array}$ & 11.38 & 6.45 & 17.83 & 4.93 \\
\hline Obesity & $\begin{array}{l}\text { Mild } \\
\text { Moderate } \\
\text { Severe } \\
\end{array}$ & $\begin{array}{l}173 \\
659 \\
168 \\
\end{array}$ & $\begin{array}{l}17.30 \\
65.90 \\
16.80 \\
\end{array}$ & $\begin{array}{c}0-7 \\
8-21 \\
22-45\end{array}$ & 14.58 & 7.40 & 21.93 & 7.13 \\
\hline
\end{tabular}

\section{DISCUSSION}

The prevalence of eating disorder among the population in this study was $17 \%$. This finding was consistent with other African findings. This finding are comparable to a South African data which established prevalence rates of $17.9 \%$ for black female adolescents and $21.2 \%$ for white female adolescents ${ }^{18}$. A Nigerian prevalence figure for abnormal eating attitudes of $18.6 \%$ was established ${ }^{13}$. Their sample was black and urban in location, comprising secondary school pupils and university students. An Egyptian study 12, conducted at a secondary school in Cairo established a prevalence rate for abnormal eating attitudes of $11.4 \%{ }^{32}$. A study conducted amongst white adolescents in Cape Town revealed the prevalence of abnormal eating attitudes to be $15 \%$ amongst the female respondents ${ }^{34}$.

Another study showed that $29.2 \%$ of rural adolescent girls had eating disorders, suggesting that this is a significant disordered eating attitude and behavior with more than a quarter of the population studied affected $^{35}$. A different study, conducted on a rural college campus, found that $17 \%$ of $18-19$ years old respondents fell in the high risk category for developing an eating disorder ${ }^{35}$. Prevalence of eating disorder such as anorexia nervosa and bulimia nervosa are lower in non-western countries than that of western countries ${ }^{36}$. The National Institute of Mental Health estimates showed that approximately $15 \%$ of teenagers in high school engage in these disordered eating behaviours ${ }^{37}$. However, studies of community-based samples conducted in South Africa, Zimbabwe, Egypt and Nigeria during the 1980s and $1990 \mathrm{~s} \quad 138^{2} 15$ (provided support for the hypothesis that the western epidemic of eating disorders has arrived on the African continent. The prevalence of abnormal eating attitudes was equally common in black, mixed-race and white urban girls aged between 15 and 18years ${ }^{16}$.

Based on the findings from this study anorexia nervosa $(20.5 \%)$ is the most common type of eating disorder among the study population with followed by bulimia nervosa $(17.0 \%)$ and obesity $(16.8 \%)$. This was consistent with findings from a study carried out in rural Africa, which suggested that eating disorder such as anorexia nervosa may exist there and may not be a solely 'western' phenomenon ${ }^{38}$. Anorexia nervosa and bulimia nervosa have for long been considered a western disorder or the 
disorder of the developed world but the results obtained clearly indicate that this assumption is incorrect. Fifty eight $(58 \%)$ of the students involved in the study indicated a predisposition to two eating disorders; anorexia and bulimia.

Thus, it can be concluded that eating disorders are not uncommon respondents among the studied group. Affected individuals tended to self-report more severe symptoms of anorexia nervosa. Anorexia nervosa is the most common type of eating disorder among the study population.

\section{Acknowledgement: None}

\section{Conflict of Interest: None}

\section{Source of Funding: None}

\section{REFERENCES}

1. Fairburn CG, Harrison PJ, Eating disorders. The Lancet 361(9355): 407416. doi: 10.1016/S0140-6736(03)12378-1: 2003.

2. Crow SJ, Peterson CB, The economic and social burden of eating disorders: A review. Eating Disorders: John Wiley Sons Ltd, 2002.

3. Patton GC Selzer R Coffey C Carlin JB Wolfe R, Onset of Eating Disorders; population based cohort study 3 year BMJ:1999.

4. Nasser M, Culture and weight consciousness Journal of somatic research, 32,573-577: 1988.

5. Nasser $M$, The emergence of eating disorders in other cultures/societies. In Nasser M (Ed) Culture and weight consciousness ; pp 22-60, Routledge; New York, 1997.

6. Davis, C Katzman, MA Perfection as Acculturation: Psychological correlates of eating problems in Chinese male and fem ale students living in the United States. International Journal of Eating Disorders, vol. 25, pp. 65-70. John Wily Sons, Inc:1995
7. Dolan B Cross-cultural aspects of anorexia nervosa and bulimia: a review. International Journal of Eating Disorder 10:67-78: 1991.

8. Le Grange D., Telch C.F. and Tibbs J Eating attitudes and behaviours in 1435 South African Caucasian and nonCaucasian college students. American Journal Psychiatry 155:250 254: 1998.

9. Hooper MSH, Garner DM Application of the eating disorder Inventory to a sample of black, white and mix race school girls in Lanshire ,international journal of eating disorder 5:161-168: 1986.

10. Nasser M, Comparative study of prevalence of abnormal eating attitudes among Arabian female students of both London and Cairo Universities psychological machine 16,621-625 :1986.

Doi.10.1017/50033291700010320

11. Nasser M, Screening for abnormal eating attitude Egyptian secondary school girls. Social psychiatry and psychiatric Epidemology,29,25-30: 1994

12. Jones BC, AC little, Penton-Voak, BP Tiddeman DM Burt, DI Perrett Facial symmetry and judgements apparent health support for a "good genes" explanation of the attractivenesssymmetry relationship Evolution and Human Behaviour 22, 417-429: 2001.

13. Oyewumi, L. K. and Kazarian, S. S. Abnormal eating attitudes among a group of Nigerian youths: I. Bulimic behaviour. East African Medical Journal, 69, 663-666:1992.

14. Wassenaar, D.R., Le Grange D, Winship $\mathrm{J}$, and Lachenicht L., The prevalence of eating disorder pathology in a crossethnic population of female students in South Africa. European Eating Disorders Review. 8, 225-36: 2000.

15. Senekal, M., Steyn N.P., Mashego T.B. and Nel J.H. Evaluation of body shape, eating disorders and weight management parameters in black female students of rural and urban origins. 
South African Journal of Psychiatry. 31:45-53: 2001.

16. Caradas AA, Lambert EV, Charlton KE An ethnic comparison of eating attitudes and associated body image concerns in adolescent South African schoolgirls. Journal Human Nutrition Dietet. 14: 111-120: 2001.

17. Szabo and Hollands Factors influencing eating attitudes in secondary school girls in south Africa- a preliminary study, S Afri Med J Apri 87 (4 supp); 531-4: 1997.

18. Al-subaje A- Al Shammari S. Bamgboye E Al- Sashan K, Al Sheri s, Bannah AR validity of the Arabic version of the eating attitude Test Inter.J eating disorder. 20, 321-324: 1996.

19. World Health Organization, Preventing chronic diseases: untal investment: WHO global report. IRIS institutional repository for information sharing 2005.

20. Jones JM, Bennett S, Olmsted MP, Lawson M L, Rodin G Disordered Eating and behaviours in teenage girls: A school-based study. Canadian Medical Association Journal, 165, 547:552: 2001.

21. Go'testam, K, Agras, W General population-based epidemiological study of eating disorders in Norway. International Journal of Eating Disorders, 18, 119 126: 1995.

22. Shuriquie N Eating disorders: A transcultural perspective. Eastern Mediterranean Health Journal, 5, 354360: 1999.

23. Al-Subaie, A Al-Shammari, S Bamgbove, E Al-Sabhan, K Al-Shehri, $S$ Bannah, A Validity of the Arabic version of the eating attitude test. International Journal of Eating Disorders, 20, 321-324: 1996.

24. Nobakht M, Dezhkam An epidemiological study of eating disorder in Iran December 2000 International journal of eating disorders 28 (3); 265$71 ; 2001$.

25. Afifi-Soweid, RA, Kteily MB, ShediacRizkallah MC Preoccupation with weight and disordered eating behaviors of entering students at a university in Lebanon. International Journal of Eating Disorders, 32, 52-57:2002.

26. Bruch $H$ The Golden Cage: The enigma of anorexia nervosa. New York: Vintage Books: 1978.

27. British Broadcasting News, Health, 2000

28. Fairburn CG, Cooper Z, Doll H, Davies B, Identifying dieters why will develop an eating disorder: a prospective, population based study. American Journal of Psychiatry 2005: 16(12):2249-55.

Doi:10.1176/appi.ajp.162.12.2249.

29. Gordon KH, The classification of Eating Disorders. In Mitchell JE and Peterson CB (Eds); Assessment of eating disorders, pp. 17-31, Guilford Publications 2005.

30. Slverstein B, Perlick D The cost of competence : why inequality causes Depression, Eating disorders and illness in women: 1995.

31. Bemoprad J, Aspect of psychotherapy with adult with attention deficit disorder Ann; NY Acad Si. Jun, 931; 302-9: 2001. DOI; $\quad 10.111 /$ j.17496632.2001.tb05787.x

32. Garner DM, Garfinkel, PE The eating attitudes test: An index of the symptoms of anorexia nervosa. Psychological Medicine, 9, 273-279:1977.

33. Garner DM, Psycho-educational principles in treatment for Eating disorders, 2nd edition Guilford: 1997.

34. Le Grange D, Tibbs J, Selibowitz J, Eating attitudes, body shape, and self disclosure in a community sample of adolescent girls and boys. Eating Disorders: J Treatment and Prevention 3: 253- 264: 1995.

35. Becker A, The contemporary study: television and eating disorder in Fiji. Pychology Wizard: 2002.

36. Makino M, Tsuboi k, Dennerstein L. Prevalence of eating Disorders: a comparison of western and non western 
Adebimpe Oluwafisayo A et.al. Prevalence of eating disorders among female undergraduates at a Nigerian University.

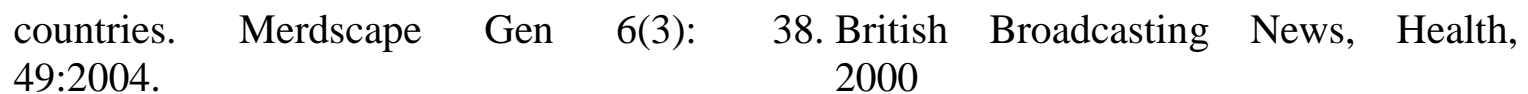

37. The National Institute of Mental Health, Eating disorders; national institute of mental health perspective Chavez $\mathrm{m}$ insel TR. American psychologisy62(3), 159-166:

2007 https;//doi.org/10.1037/0003066X.62.3159
How to cite this article: Adebimpe Oluwafisayo A, Idehen EE, Mosaku SK et.al. Prevalence of eating disorders among female undergraduates at a Nigerian University. Int J Health Sci Res. 2021; 11(10): 118-125. DOI: https://doi.org/10. 52403/ijhsr.20211015

$* * * * * *$ 